\title{
PROMOÇÃO DE SAÚDE BUCAL EM ESCOLARES DA REDE MUNICIPAL DE ENSINO DE CAMPO LARGO E REGIÃO METROPOLITANA DE CURITIBA
}

Gabriel Leonardo MAGRIN, Taryn Torres CAPOBIANCO, Sharon MOREIRA, Cintia Ligia OLICHEVIS, Vânia Aparecida VICENTE

O projeto envolve a análise das condições de saúde dos escolares pertencentes à rede municipal de ensino da região metropolitana de Curitiba e Rural de Campo Largo. A condição de saúde bucal é avaliada por meio de anamnese, exames clínicos bucais e laboratoriais, realizados através da análise microbiológica da saliva, visando o levantamento da ocorrência de doença cárie na população estudada. A cárie é uma doença infecciosa, multifatorial prevalente na infância, sendo a bactéria Streptococcus mutans principal agente etiológico, existindo uma correlação entre concentração desta com a incidência da doença. Esta doença vem sendo controlada através da execução de procedimentos individuais e coletivos, especialmente os de cunho educativo-preventivo. Os resultados são compilados e apresentados para a comunidade escolar. A participação ampla da comunidade nas atividades e os altos índices de incidência para a doença avaliada mostra a necessidade de intervenção na população atendida. O projeto vem desempenhando um papel importante no diagnóstico precoce e repasse de conhecimento, minimizando problemas sociais decorrentes da ausência de ações profiláticas e de infraestrutura nestas comunidades.

Palavras-Chaves: Doenças da Boca, Saúde bucal, Promoção da Saúde, Prevenção. 